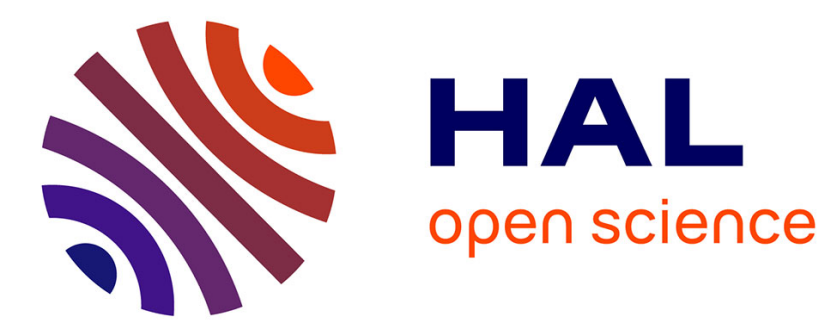

\title{
It ain't what you do, it's the way that you do it: Characteristics of procedural justice and their importance in social decision-making
}

Paul Dolan, Richard Edlin, Aki Tsuchiya, Allan Wailoo

\section{- To cite this version:}

Paul Dolan, Richard Edlin, Aki Tsuchiya, Allan Wailoo. It ain't what you do, it's the way that you do it: Characteristics of procedural justice and their importance in social decision-making. Journal of Economic Behavior and Organization, 2007, 64 (1), pp.157. 10.1016/j.jebo.2006.07.004 . hal00531864

\section{HAL Id: hal-00531864 \\ https://hal.science/hal-00531864}

Submitted on 4 Nov 2010

HAL is a multi-disciplinary open access archive for the deposit and dissemination of scientific research documents, whether they are published or not. The documents may come from teaching and research institutions in France or abroad, or from public or private research centers.
L'archive ouverte pluridisciplinaire HAL, est destinée au dépôt et à la diffusion de documents scientifiques de niveau recherche, publiés ou non, émanant des établissements d'enseignement et de recherche français ou étrangers, des laboratoires publics ou privés. 


\section{Accepted Manuscript}

Title: It ain't what you do, it's the way that you do it:

Characteristics of procedural justice and their importance in social decision-making

Authors: Paul Dolan, Richard Edlin, Aki Tsuchiya, Allan

Wailoo

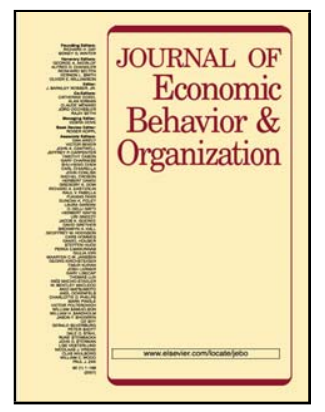

PII: S0167-2681(07)00063-7

DOI: doi:10.1016/j.jebo.2006.07.004

Reference: JEBO 2089

To appear in: Journal of Economic Behavior \& Organization

Received date: $\quad$ 13-6-2005

Revised date: $\quad 1-6-2006$

Accepted date: $\quad$ 7-7-2006

Please cite this article as: Dolan, P., Edlin, R., Tsuchiya, A., Wailoo, A., It ain't what you do, it's the way that you do it: Characteristics of procedural justice and their importance in social decision-making, Journal of Economic Behavior and Organization (2007), doi:10.1016/j.jebo.2006.07.004

This is a PDF file of an unedited manuscript that has been accepted for publication. As a service to our customers we are providing this early version of the manuscript. The manuscript will undergo copyediting, typesetting, and review of the resulting proof before it is published in its final form. Please note that during the production process errors may be discovered which could affect the content, and all legal disclaimers that apply to the journal pertain. 


\title{
It ain't what you do, it's the way that you do it: Characteristics of procedural justice and their importance in social decision-making
}

\author{
Paul Dolan ${ }^{1}$, Richard Edlin ${ }^{2}$, Aki Tsuchiya ${ }^{2,3}$, Allan Wailoo ${ }^{2^{*}}$ \\ ${ }^{1}$ Tanaka Business School, Imperial College, London, UK \\ ${ }^{2}$ Health Economics and Decision Science, School of Health and Related Research, \\ University of Sheffield, UK. \\ ${ }^{3}$ Department of Economics, University of Sheffield, UK
}

\begin{abstract}
Standard welfare economic analysis evaluates all actions by their consequences.

However, evidence from other disciplines suggests that the procedures by which

decisions are made also affects the welfare of individuals. This paper outlines six

characteristics on which judgements about procedural justice may be based. Using the example of health care rationing, we examine the importance of each characteristic using qualitative and quantitative methods. We further consider the importance of each of these characteristics relative to one another and examine whether they are important for consequential or non-consequential reasons.
\end{abstract}

Key words: Welfare economics, procedural fairness, consequentialism.

JEL classification number: D60, D70

\footnotetext{
${ }^{*}$ Corresponding author.

Health Economics and Decision Science, School of Health and Related Research, University of Sheffield, Regent Court, 30 Regent Street, Sheffield. S1 4DA. UK.

Tel: 0044114 2220729, Fax: 0044114 2724095,Email: a.j.wailoo@sheffield.ac.uk
} 


\section{Acknowledgements:}

This work was funded by a grant from the UK Arts and Humanities Research Board (Project Number 13789). We would like to thank Paul Anand, Norman Daniels, Dan

Wikler and participants at seminars held in Harvard and Oslo for their helpful comments on earlier versions of this paper. We would also like to thank Luís Miguel and Rebecca Shaw for helping us administer the questionnaires and the respondents for taking the time to fill them in. 


\section{Introduction}

At the heart of standard welfare economic theory lays utilitarianism, a philosophy that requires that every choice must ultimately be judged by the consequent states of affairs. Within economics more generally, this consequentialist foundation has traditionally been applied in a narrow sense, whereby only the impact on the utility associated with different possible outcomes is considered. This narrow consequentialist approach does not, for example, consider any utility that might be generated from the ways in which alternative states of the world are determined. Insofar as the procedures used to make decisions matter, they are valuable only to the extent to which they promote utilityyielding outcomes.

There has been increasing recognition that economics should develop a wider conception of utility that includes considerations besides consequences. Hahn $(1982,188)$, for example, in describing the utility generated from alternative policy decisions, states that: "My utility may not only depend on what I get but on the manner in which I get it. That is my utility may not only depend on the consequences of policy but on the policy itself." Similarly, $\mathrm{Ng}(1988,217)$ argues that: "if people prefer one-person-one-vote, the use of this method directly yields utility. This is a fact that cannot be ignored." Some of the most conspicuous criticisms of the exclusion of procedural considerations have been made by Amartya Sen (Sen and Williams 1982, Sen 1997, Sen 2002), who argues that the failure to acknowledge procedural preferences may lead to biases in the ranking of policies.

There is now empirical evidence that suggests that the ways in which decisions are made, and the reasons that underlie them, can affect people's reactions to, and utility from, 
those decisions. Kahneman et al. (1986) presented members of the public with a range of hypothetical scenarios where the price of a commodity had risen to rectify market disequilibria. Although the consequences of these price rises were all the same, the reasons for the price rises differed, and respondents made very clear distinctions between the firms' actions in terms of perceived fairness. In particular, price rises due to supply changes were "fair", but equivalent rises due to increased demand were "unfair". Bies et al. (1993) developed this issue further and found that procedural justice was an important determinant of perceived fairness. For example, the degree to which firms involve workers in discussions about pay cuts substantially affected the perceived fairness of those cuts. Frey and Pommerehne (1993) conducted a similar study with German and Swiss populations and found that raising prices to ration demand was considered less fair than allocation by a "first come, first served" rule or allocation by an authority.

Further empirical work into procedural preferences in economic contexts has been conducted (notably by Bruno Frey and colleagues) in a number of decision-making scenarios, focusing in particular on the decision of where to site environmental hazards such as toxic waste dumps and radioactive waste facilities. Pommerehne et al. (1997) compare alternative allocative mechanisms and find that expert judgement is considered acceptable by over half their sample, ahead of (and in descending order of preference) layperson judgement, allocation by lottery, and an auction mechanism. Frey and Oberholzer-Gee (1996) find that solutions using monetary values (based on willingness to pay or willingness to accept) to determine the location of sites are the least acceptable of all the solutions they consider. Frey et al. (1996) argue that the poor performance of solutions relying on compensation is because 1) compensation is regarded as a form of bribe (that is, a system using compensation is seen to be morally wrong), and 2) 
compensation is typically inconsistent with a public spirited acceptance of an unwanted facility (that is, offering compensation "crowds-out" public spiritedness).

Yet despite these studies, our understanding of procedural justice in economic contexts and the relevance of the concept to policy-makers remains limited. In particular, while procedural justice captures a number of different procedural characteristics (such as consistency, transparency, and so on), we have very little idea about which of these characteristics matter most to people and what relationships there might be between them. By taking note of the relative importance of different procedural characteristics, decision makers would be able to adjust their existing procedures to increase the chances that individuals will support even apparently unfavourable decisions. The different procedural characteristics have been discussed at some length in social psychology and legal studies (see, for example, the seminal works of Thibaut and Walker 1975, Lind and Tyler 1988) but there has been very little empirical work on the relative importance attached to the different procedures.

In addition, this literature typically deals with decision-making at an individual level. Whilst procedural preferences have been discussed at the societal level, for example, Daniels and Sabin (1997 and 1998) in the context of health care, empirical evidence at this level is relatively scarce. Of the papers testing procedures at the societal level, Wailoo and Anand (2005) established the significance of procedures similar to those below, although they make no claims as to their relative importance (see also papers by Aquino et al. 1992 and Syme and Fenton 1993).

This paper has three main aims. The first is to consider whether the same set of procedural characteristics that have been identified as important in the fields of social 
psychology and legal studies are also important in a social choice context. The second is to provide tentative evidence on the relative importance attached to the different characteristics. The third aim of this paper is to consider the reasons why some procedural characteristics matter.

Here, we distinguish between three reasons: first, procedures might matter simply because they promote better outcomes (a narrow consequentialist view corresponding to the traditional welfare economics approach); second, they might matter because they have inherent value in their own right (a pure proceduralist view); third, they may be important because they promote factors other than consequences that individuals value (a non-consequential, instrumental view). Any particular procedural characteristic may be justified using a combination of these three reasons. For example, a decision-making mechanism that consults with members of the general public may be preferred because members of the local community know best about what is needed, so consulting them will lead to best outcomes; or because democracy means consulting constituent voting public regardless of how it contributes to the decision itself; and/or because consultation conveys respect from the decision maker.

A literature review and three studies were conducted. The review highlights the specific characteristics of decision-making that have been examined (and shown to be important) in individual, organisational and social decision-making contexts, and also considers those studies that have assessed the relative importance of different procedural characteristics. The review forms the basis for the empirical studies that test the relevance of these procedural characteristics in the context of health care rationing, which serves as an example of a social choice problem. In what follows, Section 2 discusses the characteristics of procedural justice that were identified from the literature 
review, Section 3 outlines the study methods, Section 4 presents the results, and Section 5 provides some discussion and concluding remarks.

\section{The importance of different procedural characteristics}

A systematic literature review was conducted in order to identify and classify potentially relevant procedural characteristics. To identify relevant publications, we used keyword searches of electronic databases and hand searches of specific journals and papers by specific authors. Full details of the review are available from the authors on request. A total of 107 potentially useful articles and books were identified from across a range of decision-making contexts. Most works referred to scenarios within legal or organisational settings (which include areas such as dispute resolution, performance appraisal, pay determination, and hiring decisions) rather than social choice scenarios. Across these contexts, the theoretical literature on procedural justice can be summarised using six broad procedural characteristics: voice, neutrality, consistency, accuracy, reversibility and transparency.

\subsection{The procedural characteristics}

Voice refers to the means by which those who are affected or potentially affected by a decision have the opportunity to contribute to the decision making process. This may either be directly or via some type of representation, a distinction that Anand (2001) refers to as macro versus micro voice. Furthermore, the type of involvement in the decision making process may take the form of information giving, as in the right of a defendant to give evidence in courtroom trials, or may extend to some involvement in the actual process of making decisions, as in the inclusion of public or patient 
representatives on health care decision making bodies. A total of 46 out of the 107 papers empirically investigated at least one element of voice, and 44 of these found some evidence in support of it.

Regardless of the degree to which those affected by decisions are included in the process, neutrality requires that decision-makers are able to separate themselves from preconceptions and self-interest (Magner et al. 2000). Variants of neutrality exist that focus on the trust placed in decision-makers and a belief in their honesty. Perhaps the most obvious example of this type of bias suppression is the requirement for declarations of interest operated by many academic journals and decision-making committees, although these tend to focus on potential vested interests that arise from pecuniary rewards. Fifteen papers specifically tested some form of neutrality, and in each case an element of this characteristic was supported.

Whilst neutrality may require that the interests of similar people within a process be treated in the same way, there is still potential for individuals to be afforded different roles within the process. For a process to satisfy consistency, however, the roles accorded to similar people (including the degree to which they may make representations to the decision-maker) must also be the same (Leventhal 1980). In addition, procedural consistency may be thought of as the requirement that the same decision making criteria are applied across both a significant time period and across a range of comparable decision contexts. Eight papers elicited preferences over consistency, and five of these found support for this procedural characteristic.

Any decision-making process requires some mechanism for assessing the relevance and accuracy of different types of information. In conjunction with neutrality and 
consistency, the use of accurate information leads to decisions being made on the basis of evidence rather than personal bias or other vagaries of the decision-making process. As the parties to a dispute or the opinions of the general public form a potential source of information on which decisions could be made, there will be some overlap with voice. In particular, within contexts such as job selection and legal disputes, the parties concerned will hold some of the most pertinent information to the decision. Accuracy therefore refers to both the fitness for use of the information that informs decision makers and the competencies of those responsible for making the decisions. Accuracy was tested in twelve papers, eleven of which found support for some aspect of it.

On procedural justice grounds, a group facing an unfavourable outcome can be argued to have a right to appeal an unfavourable decision (within certain restrictions, such as where due process was violated or where new facts became available) and this requires some degree of reversibility of the decision. Where these arguments are seen to be convincing, it is reasonable that a decision may be reversed or compensation awarded when this is not possible. The effect of reversibility procedures is to govern the restrictions on when claims can be made and how appeals will proceed. Overall, reversibility was tested in five studies and found to be significant in four of them.

The final procedural characteristic identified was transparency. At the individual level (in legal settings, for example, where a person is intimately involved in the process), it is relatively hard to deny affected parties information that was relevant to how the decision was made. In social decision-making contexts, however, there is no guarantee that it will be clear how a decision was reached. Where information about the process is lacking, the ability of a person to see what procedures are in use and whether procedural rules 
were followed is hampered. Transparency was tested in five papers, with a form of it found to be important in two.

\subsection{The relative importance of the procedural characteristics}

Since Leventhal (1980) noted the lack of empirical evidence about the relative importance of different sets of procedural characteristics, only fourteen studies were identified in the review as providing data on more than one of the procedural characteristics. ${ }^{1}$ Although each of these studies considered two or more procedures, none could provide information on trade-offs. The statistical tests precluded trade-offs being found (for example, Hartman et al. 1999), or the methodology was unclear (for example, Tyler 1994), or inappropriate methodologies were used for the categorical data (for example, Truxillo et al. 2001).

For these reasons, we were not able to draw any firm conclusions from the existing literature about the relative importance of different procedures. Moreover, it should be noted that studies have described the different procedural characteristics in a variety of ways. The relative importance of procedural characteristics, like the importance of many other things in life, is likely to be highly context-specific, and we should be very cautious about drawing inferences for social level decision-making from the results of studies that have looked at individual level decision-making. Finally, decision-making bodies cannot assess the importance of procedural preferences until the reasons why these procedures are important are better understood.

\footnotetext{
1 Typical examples were pay and promotion awards (Jones et al. 1999) and reactions to the editorial decisions of publishers (Gilliland and Beckstein 1996).
} 


\subsection{Why procedural characteristics might matter}

To understand better the role that procedures might play in decision-making, we need to know whether procedures are valued for their effects on consequences, on other factors, or simply in their own right. The distinction is important for economists whose outcome oriented viewpoint may be challenged either for its failure to address deontological considerations or for being too narrow a version of consequentialism. Where procedures generate no intrinsic value, but can be expressed solely in terms of their impact on outcomes, they have no direct importance for assessments of social welfare. In other situations, where procedures are valued either for their impact on non consequential factors or are viewed as inherently valuable in themselves, then social welfare cannot be assessed without reference to procedure. Currently, there exists little evidence in this regard.

There is clearly instrumental value to voice in that it allows a degree of control over decision-making, or at least gives the impression of control (Thibaut and Walker 1975, 1978). Using a legal dispute setting, Thibaut and Walker (1975) distinguish between control over the final decision (decision control) and control over the presentation of evidence (process control). In addition, it has been argued that voice generates value through the impact on dignity and social standing (for example, Tyler and Lind 1992, Tyler et al. 1996, Jones et al. 1999); that is, it generates values for reasons beyond those captured in a consequentialist framework. Furthermore, the 'value-expressive' aspect of voice refers to the inherent value that people ascribe to the ability to state their case, irrespective of the impact that this may have on the actual decision (Tyler et al. 1985). 
Despite the recognition of the importance of neutrality, no study that we are aware of has distinguished between inherent and instrumental value, or between consequential or non-consequential importance. The pure procedural view of consistency is that a decision might be seen as unfair when evaluated according to its consequences alone (perhaps because of its distributional consequences) but might nonetheless be seen as fair overall if it can be demonstrated that procedures have been applied in a consistent manner. Individuals could also see procedural consistency as a means of promoting decisions (and resultant consequences) that are themselves more consistent across persons and over time.

The extent to which information used in decision-making is accurate and up-to-date has a clear and direct instrumental value in promoting better outcomes. However, there may be additional value associated with this procedural characteristic in that the investment in gathering more accurate information in the first place signifies that making the 'right' decision matters, which thus conveys respect for those potentially affected by those decisions. Again, no evidence was found that tested the importance of the distinction between instrumental and non-instrumental reasons for valuing increased accuracy.

Decision-making mechanisms that incorporate some element of appeal and reversibility of decisions have clear benefits in terms of promoting better outcomes provided that the mechanisms that led to the initial decision are in some way imperfect and the appeal mechanism employs different criteria or additional information. There is, however, a recognised requirement for the provision of appeal in legal scenarios in situations where procedural rules have been violated, for example, the ability to appeal "on a technicality", which implies that reversibility is not solely valued for consequential purposes. In this situation, reversibility is dependent on other characteristics of the decision process. 
Furthermore, individuals may value appeals not only for their ability to lead to better outcomes on average, but also for the opportunity they provide for their voice to be heard and for their function in providing a forum in which any disagreement with the decision can be formally registered.

The instrumental importance of transparency is likely to be related to the need for reversibility in a decision making process. Transparency allows individuals not responsible for decision making to scrutinize the information and logic applied to that information. This in turn allows those external to decision making to assess the outcome of that process and launch appeals where the decision itself is considered "incorrect". In addition to this instrumental and consequential value, transparency is required in order to assess whether the procedural rules of decision-making have been adhered to, which may in turn be a cause for appeal.

Evidence of how these different procedural characteristics impact upon assessments of decision making in social choice scenarios is limited, as is evidence of how these assessments are related to concerns for the eventual outcomes of the decisions. Further empirical investigation is therefore required in order to locate existing evidence from psychology and legal studies in a wider context that can ultimately inform institutional design and other elements of public policy. In the following section, we describe three studies that attempt to provide such evidence using the issue of health care rationing as an example of social choice. 


\section{Study methods}

One set of focus group discussions and two questionnaires were used in order to investigate which procedures matter, how much they matter relative to one another, and why they matter, within the context of social decision-making. The focus groups looked at which procedural characteristics matter, the first questionnaire looked at the relative importance of the procedural characteristics, and the second questionnaire looked at whether procedural characteristics are valued for their instrumental or inherent value.

All the studies focused on a health care rationing decision as an example of a social choice problem. The issue of how best to use scarce health care resources is one that faces all health systems. Whilst a number of contributions have been made to identify the importance of both efficiency and equity-based consequentialist criteria for making such decisions (see Dolan and Olsen 2002), it is not clear that any contentious decision, particularly one that may involve the denial of health care to particular individuals, will be acceptable to the public unless the public is satisfied that the procedures used to make such tough decisions have been fair (Wailoo and Anand).

The focus groups gave participants the opportunity to discuss, justify, reflect upon and amend their opinions about how planning decisions should be undertaken. A sample of the general public in Sheffield, UK, was invited by letter to attend focus group discussions for which they were offered a small amount of money. Eight groups were held involving 54 participants. A facilitator, who first described a health care rationing scenario to them, led each group. The scenario described was that of a UK National 
Health Service (NHS) health authority that experienced an unexpected change in its budget mid-way through a financial year. ${ }^{2}$

In half of the groups, the scenario described an unexpected budget increase, whilst in the other half this was a budget decrease. This distinction was made to control for the fact that preferences may differ in response to social gains as opposed to losses in the same way as individual preferences have been found to (Rabin 1998). Participants were asked to discuss the means by which they would make the necessary funding decisions. Intervention from facilitators from this point was minimised. Clarifications were given where required, but the primary role of the facilitator was to steer discussions back to the issue in question where they diverged. Discussions were transcribed and analysed by two researchers by coding text into categories based on the procedural characteristics identified from the literature review.

The first questionnaire was administered on a different sample of the general public, also from Sheffield, UK. These individuals were invited by letter to attend discussions about more general priority-setting issues in health care (not discussed in this paper; Tsuchiya et al. 2005), for which they were offered a small amount of money. A sample of 128 people attended a total of 24 focus group discussions. At the end of these groups, respondents were briefed about what was required of them in relation to this study, which included a brief definition of each of the six procedural characteristics and a description of the UK's National Institute for Clinical Excellence (NICE). ${ }^{3}$ In total, 87 (68\%) responses were received.

\footnotetext{
${ }^{2}$ This type of organisation has responsibility for the health care needs of a regional population (approximately 500,000 people in our example).

${ }^{3}$ NICE was set up in the UK NHS in England and Wales in April 1999 "to provide patients, health professionals and the public with authoritative, robust and reliable guidance on current best practice" (see
} 
The question (reproduced in Appendix $1^{4}$ ) asked respondents to express their preferences on the relative importance of the six procedural characteristics. The question specified (entirely hypothetically) that NICE currently performs at a medium level (on a high-medium-low scale) on each procedural characteristic. ${ }^{5}$ The question then asked which characteristic the respondent would choose to improve should additional resources be made available. Each respondent was then asked to choose his or her second choice, third choice, and so on. This exercise produced a ranking of the six characteristics. The data were summarised using Borda scores and the Thurstone indices. ${ }^{6}$ Both Borda scores and the Thurstone indices represent the degree by which a given characteristic is preferred over another in cardinal terms. While neither is a perfect measure of aggregated rank order data, agreement between them offers insight regarding the robustness of the results given their different theoretical foundations.

The second questionnaire was initially administered on the participants in the focus groups of the first study (with 49 out of 54 completed responses). In order to increase sample size, an additional 48 respondents were recruited from university students. ${ }^{7}$ These participants were provided with background material similar to that discussed in

www.nice.org.uk). In 2005, this body was succeeded by the National Institute for Health and Clinical Excellence, which retained the acronym.

${ }^{4}$ Available on JEBO website

${ }^{5}$ It was necessary to specify the current state (medium for all characteristics) because without this information, individuals may choose based on their (unobserved) preconceptions about its performance, which would make interpreting the results problematic. For example, if a respondent felt that NICE was performing well on characteristic $\mathrm{X}$ and poorly on characteristic $\mathrm{Y}$, she may be more likely to rank $\mathrm{Y}$ above $\mathrm{X}$ even if characteristic $\mathrm{X}$ is considered more important.

${ }^{6}$ Borda scores for a characteristic is based on the ranking given to it by each respondent. If it is ranked first by one respondent, this counts as a score of 6 , if ranked second by two respondents, then this counts as a score of $5 \times 2=10$, and so on. The average Borda score for each characteristic is then calculated across respondents. Thurstone index for a characteristic is derived from the proportion of times it is ranked higher than all the other characteristics. A normal distribution is assumed and the probabilities transformed into z-values, which gives the Thurstone index. We report both scores that are standardised between 0 and 1 , between the most and least preferred procedural characteristics, respectively. 
the focus groups. All respondents answered three questions (reproduced in Appendix 2) designed to highlight the distinction between the narrow consequentialist and procedural viewpoints.

\section{Results}

\subsection{Do procedural characteristics matter?}

Table 1 reports the numbers of focus groups that discussed each of six procedural characteristics without prompting from the facilitator. On average, each group raised three procedural characteristics, but substantial differences were noted in the frequency with which each characteristic was discussed. Voice and accuracy were discussed most frequently (six out of eight groups), whereas consistency was mentioned in only one of the groups. Participants who initially raised particular procedural characteristics did so in a positive manner; that is, they referred to particular ways in which decision-making ought to proceed. Subsequent contributions from other participants were not always positive. Participants sought to justify these attitudes in discussions and, in so doing, drew on broader consequentialist and purely procedural arguments.

Discussions relating to the concept of voice suggested strong support for consultation with members of the public as a general principle. Some respondents expressed misgivings about specific types of consultation, but none expressed negative opinions about voice per se. In some cases, the general public were seen as a valuable information source for the NHS to identify needs and to reflect public preferences. This was

\footnotetext{
${ }^{7}$ All analyses included comparisons of the results from the two subsamples but no significant differences were found.
} 
particularly the case where respondents recognised that rationing decisions entail value judgements and felt that, as taxpayers, their own values judgements were important. In addition, several respondents felt that public involvement in decision-making was a right, often closely associated with a notion of citizenship or democracy:

\#3, Group 1: I think it would be worth spending that money [on consultation], because that is the whole point of having a democracy.

All groups expressed either prompted or unprompted concerns about neutrality and the involvement of those with vested interests in decision-making. This recognition extended to members of the general public:

\#8, G2: Everybody has something to say about it and has a vested interest in it.

It was often argued that neutrality would be achieved by involving several representatives whose biases offset each other. Additionally, it was recognised that a range of professionals might have potential vested interests but that other procedural characteristics, in particular transparency, could prevent this from causing a problem.

As the question posed to the focus groups considered a one-off decision to be made now, it is not surprising that discussions relating to consistency focused on regional rather than temporal issues. Procedural consistency (consistency of the decision making process across locations) arose in six of the discussions and the potential conflict with geographic consistency (consistency of the conclusion across locations) featured prominently, with a number of individuals expressing a clear willingness to accept variations in outcomes in favour of the application of consistent procedural rules: 
\#11, G3: I would have thought that people would be more comfortable in general with it if they used the same way to come to the conclusion of which treatment to use. They might not like that way, but I think they would see it as being a fair decision.

In most groups, individuals discussed the types of information they would seek in order to inform decision-making, and some advocated that steps be taken to ensure the accuracy of information used in the decision. For example, the commissioning of primary research and international comparisons were suggested. Interestingly, some individuals identified the opportunity cost of allocating resources towards finding increasingly accurate information in terms of both resources and delay: \#7, G4: See what you don't want to end up with is all the money being spent on you know, these decisions, you know the research, blah blab blah, to get to the decisions.

A similar recognition was apparent from some responses discussing the appropriate extent of reversibility, with the view expressed that the value of allowing challenges to decisions may depend on whether other procedural and distributional rules have been adhered to:

\#24, G5: Yes. The important thing is to get the process right. And if you've got the process right - you can only work that way. Get the process as good as you can, and then you make the decision. And that's the decision. I mean you're paralysed if the decision can keep being appealed.

Finally, the transparency of the decision making process was seen to encourage the satisfaction of other procedural rules, particularly in the scrutiny of the information used 
to make decisions (accuracy). Transparency also promotes the acceptance of decisions that might be less acceptable if evaluated solely in terms of consequences: \#7, G2: I think that if people have an adequate explanation for why something's like that then they don't feel, like we said before, they don't feel cheated. They don't feel like they're being denied something.

\subsection{Which procedural characteristics matter most?}

Table 2 (adapted from Tsuchiya et al.) reports the number of respondents in the first survey that selected each procedural characteristic as the most important, alongside the Borda scores and Thurstone indices from the ranking exercise. The rank ordering of the Borda scores and Thurstone indices are identical, and since they are derived from different sets of assumptions, this suggests the robustness of this ranking (also note the high product moment correlation of the two standardised scores). It can be seen that accuracy and consistency are the most important procedures, with transparency viewed as the least important procedure. The importance attached to consistency in this study is seemingly greater than in the focus group discussions, which may reflect the different decision making settings for the two studies. The survey questions were set at a national level in the context of an institution that has the elimination of regional variation as one of its primary aims. The two sets of results may not therefore be contradictory since failure to raise an issue unprompted is not synonymous with believing it to be less important.

\subsection{Wby do procedural characteristics matter?}


Figure 1 shows the distribution of responses to statements in the second questionnaire. Responses to negatively worded questions have been reversed, so that "disagree strongly" represents a purely consequentialist viewpoint. As the degree of "agreement" in the responses increases, the degree of non-consequential value also increases. The responses indicate that relatively few people assign a purely consequentialist value to procedures, with less than $20 \%$ of respondents indicating this in each of the three questions.

\section{Discussion}

Standard economic theory operates on a narrow consequentialist foundation that has little to say about alternative mechanisms for decision-making. However, literature from a range of other disciplines, notably social psychology and legal studies, has provided substantial empirical evidence that suggests individuals have preferences for the characteristics of allocation mechanisms in a wide variety of areas, such as pay and promotion awards, arbitration decisions and court room verdicts and sentences. While there are some exceptions, most notably the theoretical work of Sen and the empirical work of Frey and colleagues, most economic research has ignored the role of procedures and procedural justice. One key contribution of this paper has been to identify whether narrow consequentialism is limited by this exclusion and, if so, the extent to which procedural preferences can still be accounted for within a broader consequentialist framework.

Existing literature on procedural justice refers to six main procedural characteristics that have also been found to be important in individual decision-making contexts. In this paper, we report on studies that have elicited procedural preferences in the context of 
health care priority setting. The results from focus group discussions suggest that the six characteristics are of concern to participants in that all characteristics were raised in at least one of the eight focus groups without any prompting from the facilitator. The frequency with which these characteristics were raised provides some indication of the relative importance of each characteristic. The first survey asked individuals to rank these characteristics directly. In both cases, the accuracy of information used in decision-making is found to be one of the most important characteristics, and relatively little importance is attached to reversibility.

However, there are also apparent inconsistencies between the two studies; focus group discussants rarely raised the issue of procedural consistency whereas survey respondents ranked this relatively highly. The opposite was observed in relation to transparency. These findings may indicate that the importance attached to procedural characteristics is not only sensitive to individual versus social choices, but also highly context specific. Health care rationing decisions at the regional level (the subject of the focus group discussions) might not be evaluated by the same procedural characteristics as those made at a national level (the subject of the first survey). This possibility is something that should be explored in future empirical research.

The importance of procedures in social choice settings depends critically on the reasons why individuals value alternative decision-making mechanisms. If procedures have only consequential instrumental value, as the narrow version of welfare economics implicitly assumes, then procedures themselves do not directly impact upon well-being. Of course, the use of appropriate decision-making mechanisms will ensure that the consequences of health care rationing decisions will improve, and for some respondents to the second survey, this is the only purpose of considering procedures. But for 
substantial proportions of respondents this only partially describes procedural preferences. The extent to which narrow consequentialism, or consequentialism per se, must be considered insufficient varies even within the health care rationing scenario depending on how questions are asked, between attitudes to procedures as a class and between individual procedural characteristics. In all three questions that relate to Figure 1, simple instrumental consequentialism does not provide a description of the preferences of a substantial proportion of respondents. Interestingly, where the question refers directly to fairness, the importance of procedures is even greater, indicating that consequentialism per se may not be able to capture procedural preferences.

Despite caution over the generalisability of results, the central tenet remains: health care outcomes may not be the sole basis on which prioritisation decisions should be based. The data represent a modest start to our understanding of why people care about the way in which decisions are made, as well as about the consequences of those decisions. Of course, it is possible that, if pushed on the reasons for their responses in this study, respondents may ultimately value procedures for their effects on some outcome or other. In a similar way, people have been shown to value health, social relationships, and so on for their consequent effects on happiness, despite first appearances to the contrary (Bagozzi and Edwards 1998).

For instance, it is plausible that an individual values involvement in a decision irrespective of whether the decision changes in that instance. Whether an approach that incorporates procedures as well as narrow consequences should be labelled consequentialist or not is a question we do not seek to resolve here. Conceptually, it may be possible for a broader version of welfare economics to capture some of these concerns, but it is important that, in so doing, the individual utilities that go into a 
welfarist social welfare function retain their conceptual clarity. From an empirical point of the view, the real challenge is to identify the set of non-consequentialist reasons that procedures are valued for, and the studies reported here do not go particularly far in this.

The results from the studies reported here must be considered in the light of several other caveats. Firstly, health care rationing is an issue that is alien to most members of the general public, and the concept of procedural preferences is further remote. Surveys and focus group discussions were designed to provide accurate explanations of these concepts to participants but were inevitably simplistic and may not have been well understood by all participants. Secondly, the decision contexts focused on a one-off decision, where it is conceivable that the importance of consistency or reversibility may be less than in other on-going decision making scenarios. Thirdly, whilst there are inevitable relationships between procedures and consequences, the empirical element of this paper has little to say about this. An additional simplification was that no relationship between procedural characteristics was introduced. A clear challenge for the incorporation of procedural considerations into the assessment of social welfare, and the design and operation of decision-making institutions, is to account for these relationships.

Despite such caveats, the findings presented here provide further challenge to economic theory that focuses only on a narrowly defined set of consequences. We contend, as this evidence shows, that there is an important research agenda to be developed concerning the fact that we evaluate procedures alongside consequences. In addition to challenging our exclusive bias towards evaluation-by-outcome, procedural justice may further challenge key assumptions in economics. Current versions of welfare economics do not fully explain the way we view macro level institutions who choose on our behalf and 
whose decisions may have a substantial impact upon us. Outcomes are important, but procedures also play a key role in the way human beings reconcile aims against resources. As welfare economics typically takes consumer sovereignty to hold, we are left with a choice: either we look to incorporate procedural concerns into standard welfare economic theory, or we ignore procedural concerns and risk overlooking an important source of utility. If we choose not to exclude procedural preferences, we need further evidence as to the relative importance of procedures, with an aim to find eventually trade-offs between individual procedures and outcomes that will result in better social decision making. 


\section{References}

Aquino, K., Steisel, V., Kay, A., 1992. The effects of resource distribution, voice and decision framing on the provision of public-goods. Journal of Conflict Resolution $36,665-87$

Anand, P., 2001. Procedural fairness in economic and social choice: evidence from a survey of voters. Journal of Economic Psychology 22, 247-70.

Bagozzi, R. P., Edwards, E. A., 1998. Goal setting and goal pursuit in the regulation of body weight. Psychology and Health, 13, 593-622.

Bies, R.J., Tripp, T.M., Neale, M.A., 1993. Procedural fairness and profit seeking: The perceived legitimacy of market exploitation. Journal of Behavioral DecisionMaking 6, 243-56.

Daniels, N., Sabin, J., 1997. Limits to health care: fair procedures, democratic deliberation, and the legitimacy problem for insurers. Philosophy And Public Affairs 26, 303-50.

Daniels, N., Sabin, J., 1998. Last chance therapies and managed care - pluralism, fair procedures, and legitimacy. Hastings Center Report 28, 27-41.

Dolan, P., Olsen, J.A., 2002. Distributing health care: Economic and ethical issues. Oxford: Oxford University Press.

Frey, B.S., Oberholzer-Gee, F., 1996. Fair siting procedures: An empirical analysis of their importance and characteristics. Journal of Policy Analysis and Management $15,353-76$. 
Frey, B.S., Oberholzer-Gee, F., Eichenberger, R.., 1996. The old lady visits your backyard: A tale of morals and markets. Journal of Political Economy 104, 12971313

Frey, B.S., Pommerehne, W.W., 1993. On the fairness of pricing - An empirical survey among the general population. Journal of Economic Behavior and Organization 20, 295-307.

Gilliland, S.W., Beckstein, BA., 1996. Procedural and distributive justice in the editorial review process. Personnel Psychology 49, 669-91.

Hahn, F., 1982. On Some Difficulties of the Utilitarian Economist. In: Sen, A., Williams,B. (Eds.), Utilitarianism and Beyond, Cambridge: Cambridge University Press, 187-98.

Hartman, S.J., Yrle, A.C., Galle, W.P., 1999. Procedural and distributive justice: examining equity in a university setting. Journal of Business Ethics 20, 337-51.

Jones, F.F., Scarpello, V., Bergmann, T., 1999. Pay procedures - what makes them fair? Journal Of Occupational And Organizational Psychology 72, 129-45.

Kahneman, D., Knetsch, J.L., Thaler, R., 1986. Fairness as a constraint on profit seeking: Entitlements in the market. American Economic Review 76, 728-41.

Leventhal, G.S., 1980. What should be done with equity theory? New approaches to the study of fairness in social relationships. In: Gergen, K.J., Greenberg, M.S., Willis, R.H. (Eds.). Social Exchange: Advances in Theory and Practice. New York: Plenum Press, 27-35.

Lind, E.A., Tyler, T.R., 1988. The Social Psychology of Procedural Justice, New York: Plenum Press. 
Magner, N.R., Johnson, G.G., Sobery, J.S., Welker, R.B., 2000. Enhancing procedural justice in local government budget and tax decision making. Journal of Applied Social Psychology 30, 798-815.

Ng, Y.K., 1988. Economic efficiency versus egalitarian rights. Kyklos 41, 215-37.

Pommerehne, W.W., Hart, A., Schneider, F., 1997. Tragic choices and collective decision-making: An empirical study of voter preferences for alternative collective decision-making mechanisms. Economic Journal 107, 618-635.

Rabin, M., 1998. Psychology and economics. Journal of Economic Literature 36, 11-46.

Sen, A., 1997. Maximisation and the act of choice. Econometrica 65, 745-779

Sen, A., 2002. Why health equity? Health Economics 11, 659-66

Sen. A., Williams, B., (Eds.) 1982. Utilitarianism and Beyond. Cambridge: Cambridge University Press.

Syme, G.J., Fenton, D.M., 1993. Perceptions of equity and procedural preferences for water allocation decisions. Society and Natural Resources 6, 347-60.

Thibaut, J., Walker, L., 1975. Procedural Justice: A Psychological Analysis. New Jersey: Lawrence Erblaum Associates.

Thibaut, J., Walker, L., 1978. A theory of procedure. California Law Review 66, 541-66.

Truxillo, D.M., Bauer, T.N., Sanchez, R.J., 2001. Multiple dimensions of procedural justice: longitudinal effects on selection system fairness and test-taking selfefficacy. International Journal of Selection and Assessment 9, 336-49.

Tsuchiya, A., Miguel, L.S., Edlin, R., Wailoo, A.., Dolan, P., 2005. Procedural justice in public health car resource allocation. Applied Health Economics and Health Policy 4, 119-127. 
Tyler, T.R., 1994. Psychological models of the justice motive - antecedents of distributive and procedural justice. Journal of Personality and Social Psychology 67, 850-3.

Tyler, T.R., Degoey,P., Smith, H., 1996. Understanding why the justice of group procedures matters: a test of the psychological dynamics of the group-value model. Journal of Personality and Social Psychology 70, 913-30.

Tyler, T.R., Lind, E.A., 1992. A relational model of authority in groups. Advances in Experimental Social Psychology 25, 15-191.

Tyler, T.R., Rasinski, K., Spodick, N., 1985. The influence of voice on satisfaction with leaders: exploring the meaning of process control. Journal of Personality and Social Psychology 48, 72-81.

Wailoo, A., Anand, P., 2005. The nature of procedural preferences for rational health care decisions. Social Science and Medicine 60, 223-236. 
Table 1: Focus groups: unprompted discussion of procedural characteristics

\begin{tabular}{|c|c|c|c|c|c|c|c|}
\hline & Voice & Neutrality & Consistency & Accuracy & Reversibility & Transparency & $\begin{array}{c}\text { Total (characteristics } \\
\text { per group) }\end{array}$ \\
\hline Group 1 & $*$ & $*$ & & $*$ & $*$ & & 4 \\
\hline Group 2 & - & $*$ & & - & & & 1 \\
\hline Group 3 & $*$ & & * & $*$ & & $*$ & 4 \\
\hline Group 4 & & $*$ & & $*$ & & 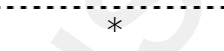 & 3 \\
\hline Group 5 & $*$ & & & $*$ & & 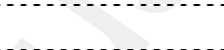 & 2 \\
\hline Group 6 & $*$ & 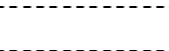 & & $*$ & $*$ & 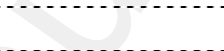 & 3 \\
\hline Group 7 & $*$ & $\cdots$ & & $*$ & $*$ & $*$ & 4 \\
\hline Group 8 & $*$ & $*$ & & & & $*$ & 3 \\
\hline $\begin{array}{l}\text { Total (groups per } \\
\text { characteristic) }\end{array}$ & 6 & 4 & 1 & 6 & 3 & 4 & \\
\hline
\end{tabular}

Table 2: Responses to questionnaire 1: the relative importance of characteristics

\begin{tabular}{lccccc}
\hline & \multicolumn{3}{c}{ First choice } & \multicolumn{2}{c}{ Scores } \\
\cline { 2 - 5 } & $\mathrm{n}$ & $\%$ & $\begin{array}{c}\text { Borda } \\
\text { (stand.) }\end{array}$ & $\begin{array}{c}\text { Thurstone } \\
\text { (stand.) }\end{array}$ & $\begin{array}{c}\text { common } \\
\text { ranking }\end{array}$ \\
\hline Voice & 17 & 20.2 & 0.52 & 0.51 & 3 \\
\hline Neutrality & 7 & 8.3 & 0.38 & 0.37 & 4 \\
\hline Consistency & 17 & 20.2 & 0.69 & 0.67 & 2 \\
Accuracy & 37 & 44.0 & 1.00 & 1.00 & 1 \\
\hline Reversibility & 4 & 4.8 & 0.25 & 0.25 & 5 \\
\hline Transparency & 2 & 2.4 & 0.00 & 0.00 & 6 \\
\hline
\end{tabular}


Figure 1: Responses to questionnaire 2: agreement to statements suggesting that procedures have non-consequential value

(i)

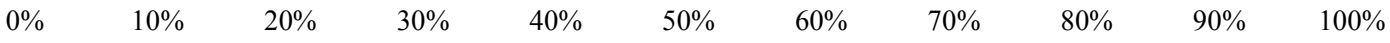

(ii)

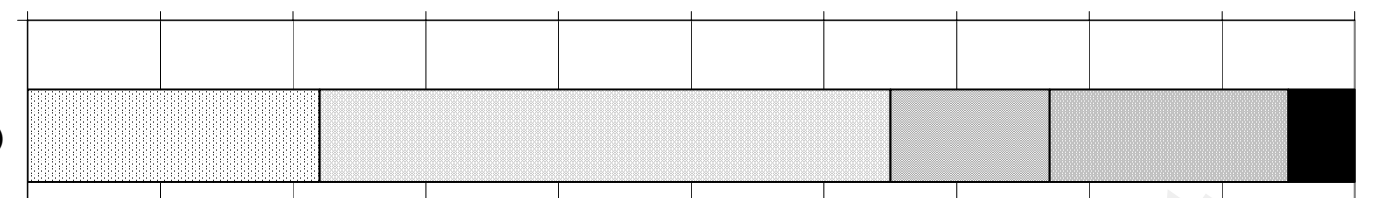

(iii)

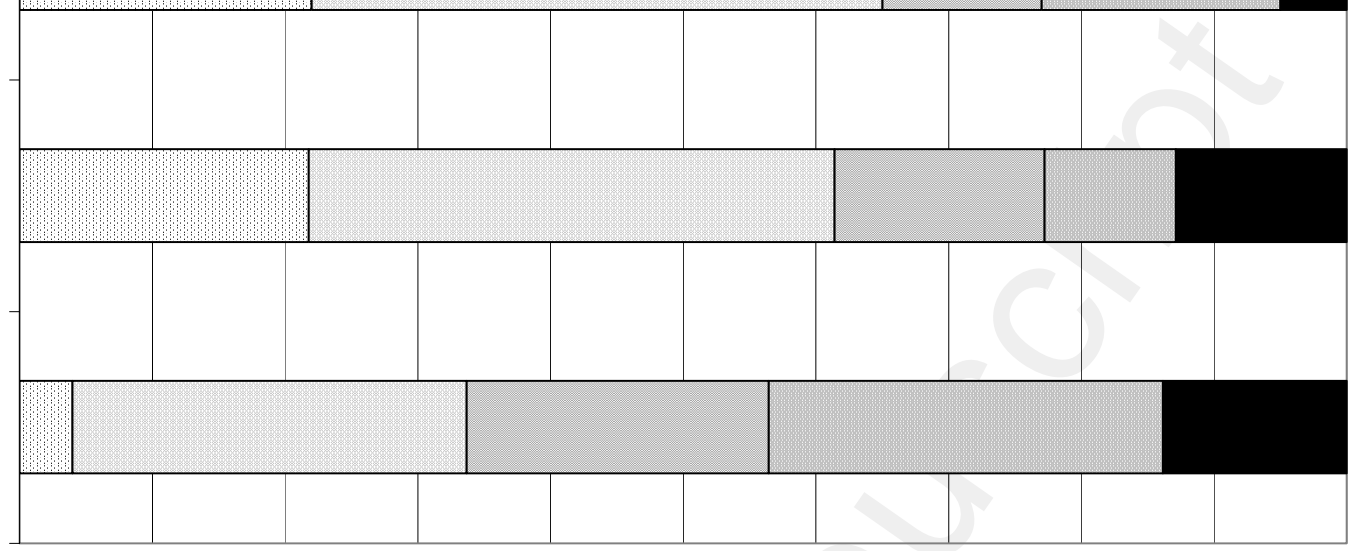




\section{Appendix 1: Questionnaire $1^{8}$.}

NICE's performance in each procedure can be classified as 'low', 'medium' or 'high'. Let us assume that NICE is at a medium level in all these six procedures:

\begin{tabular}{|l|}
\hline Accuracy \\
\hline Consistency \\
\hline Impartiality \\
\hline Reversibility \\
\hline Transparency \\
\hline Voice \\
\hline
\end{tabular}

\begin{tabular}{l|c|l|}
\hline low & medium & high \\
\hline & $\mathrm{X}$ & \\
\hline & $\mathrm{X}$ & \\
\hline & $\mathrm{X}$ & \\
\hline & $\mathrm{X}$ & \\
\hline & $\mathrm{X}$ & \\
\hline & $\mathrm{X}$ & \\
\hline & &
\end{tabular}

Imagine that some extra funds are available to change the performance of NICE in one of those six procedures. Bearing in mind that the costs of doing it are the same for all procedures, which one would you choose? Please place a ' 1 ' in the box next to your choice (in the table below).

\begin{tabular}{|c|}
\hline Accuracy \\
\hline Consistency \\
\hline Impartiality \\
\hline Reversibility \\
\hline Transparency \\
\hline Voice \\
\hline
\end{tabular}

Now imagine that even more resources are available and that you would be given the chance to choose another procedure in which you would like to change NICE's performance. Which one would you choose? Please place a ' 2 ' in the box next to it.

Please repeat the process until you have numbered all choices from ' 1 ' to ' 6 '.

If you are not happy with the final order please change it.

\footnotetext{
${ }^{8}$ Taken from Tsuchiya et al. 2005
} 
Appendix 2: Questionnaire 2

\begin{tabular}{|c|c|c|c|c|c|}
\hline $\begin{array}{l}\text { In situations where allocation } \\
\text { decisions are discussed: }\end{array}$ & $\begin{array}{l}\text { agree } \\
\text { strongly }\end{array}$ & $\begin{array}{l}\text { agree } \\
\text { to some } \\
\text { extent }\end{array}$ & $\begin{array}{l}\text { neither } \\
\text { agree nor } \\
\text { disagree }\end{array}$ & $\begin{array}{l}\text { disagree } \\
\text { to some } \\
\text { extent }\end{array}$ & $\begin{array}{l}\text { disagree } \\
\text { strongly }\end{array}$ \\
\hline $\begin{array}{l}\text { "If the decisions made are seen to } \\
\text { be acceptable, then the ways in } \\
\text { which those decisions were made } \\
\text { do not matter very much." }\end{array}$ & $\mathrm{a}$ & b & $\mathrm{c}$ & d & $\mathrm{e}$ \\
\hline $\begin{array}{l}\text { "If the final decisions made are } \\
\text { going to be the same, it doesn't } \\
\text { matter very much how these } \\
\text { decisions were reached." }\end{array}$ & $\mathrm{a}$ & b & $\mathrm{c}$ & $d$ & $\mathrm{e}$ \\
\hline $\begin{array}{l}\text { "So long as the rules for making } \\
\text { decisions are fair, then the resulting } \\
\text { decisions are bound to be fair." }\end{array}$ & $\mathrm{a}$ & b & C & $\mathrm{d}$ & $\mathrm{e}$ \\
\hline
\end{tabular}

